\title{
Case \\ Report \\ Wunderlich's syndrome with hepatic angiomyolipoma in tuberous sclerosis
}

\author{
Mongha R, Bansal P, Dutta A, Das RK, Kundu AK \\ Department of Urology, Institute of Post Graduate Medical Education and Research, Kolkata, India.
}

Correspondence to: Dr. Ritesh Mongha, E-mail: riteshmongha2001@rediffmail.com

\begin{abstract}
We present a patient of tuberous sclerosis complex with bilateral renal angiomyolipoma and hepatic angiomyolipoma with spontaneous retroperitoneal hemorrhage from right angiomyolipoma (Wunderlich's syndrome). Nephron preserving approach was tried but the right kidney could not be salvaged. Hepatic angiomyolipoma was managed conservatively. Wunderlich's syndrome has been found in around 10\% of cases of renal angiomyolipomas. Hepatic Angiomyolipoma is a benign mesenchymal neoplasm of the liver which is rarely reported in literature.
\end{abstract}

Key words: Angiomyolipoma, hepatic, renal, tuberous sclerosis.

\section{Introduction}

Wunderlich's syndrome is one of the most feared complications of renal angiomyolipoma and should be managed aggressively. $\mathrm{N}$ ephron sparing approach is preferable, especially in TS with bilateral and multicentric angiomyolipomas. $\mathrm{H}$ epatic angiomyolipomas, though rare, may be found in tuberous sclerosis, especially in patients with bilateral diffuse renal angiomyolipomas Wunderlich's syndrome refers to spontaneous nontraumatic renal bleeding into the subcapsular and/or perirenal space. The commonest cause of spontaneous renal hemorrhage in most series is an angiomyolipoma $(A M L) .^{[1]} A M L$ is a benign clonal neoplasm consisting of varying amounts of mature adipose tissue, smooth muscle and thick walled vessels. Wunderlich's syndrome represents the most feared complication of angiomyolipoma and can be fatal if not treated promptly. $\mathrm{H}$ epatic angiomyolipoma $(\mathrm{HAML})$ is a rare benign mesenchymal neoplasm of the liver. Since its first description by Ishak in 1976, not more than 200 cases have been reported in the English literature. ${ }^{[2]}$ $\mathrm{H}$ epatic angiomyolipomas, though rare, may be found in tuberous sclerosis, particularly in patients with bilateral diffuse renal angiomyolipomas.

\section{Case Report}

A 32-year-old female presented in the emergency room with sudden onset of severe abdominal pain associated with a lump in the right side of abdomen. The lump was sudden in onset; coinciding with the onset of pain; and had been increasing rapidly in size. Patient was in hypovolemic shock at the time of presentation. In addition to a palpable lump right side of abdomen, adenoma sebaceum was detected on her physical examination. She had no past history of epilepsy. After the initial management of shock, the patient was investigated. $\mathrm{H}$ er renal function tests were with in normal limits [U rea $24 \mathrm{mg} \%$, Creatinine $1.0 \mathrm{mg} \%$, $\left.\mathrm{N} \mathrm{a}^{+} 130 \mathrm{M} \mathrm{mol} / \mathrm{l}, \mathrm{K}+4.5 \mathrm{M} \mathrm{mol} / \mathrm{l}\right]$. Serum bilirubin and liver enzyme levels were with in normal limits [Total Bilirubin $1.0 \mathrm{mg} \%$, ALT $30 \mathrm{lU} / \mathrm{L}$, AST $34 \mathrm{IU} / \mathrm{L}$, Alkaline Phosphatase 160 IU/L ]. On ultrasonography highly echogenic lesion associated with shadowing was seen arising from right Kidney with hematoma extending into the perinephric space. Abdominal $U$ Itrasound also revealed hepatomegaly with multiple hyperechoic tumors in the liver.

Contrast enhanced CT-Scan KUB was done which revealed massive retroperitoneal hemorrhage from right renal tumor. Right kidney revealed multiple fat density lesions with $\mathrm{H}$ ounsefield $\mathrm{U}$ nits of -20 or lower characteristic of angiomyolipoma. L eft kidney also revealed similar multiple fat containing lesions [Figure 1]. In addition to bilateral renal angiomyolipomas, a large space occupying lesion $(8.4 \times 7.2 \mathrm{~cm})$ was 


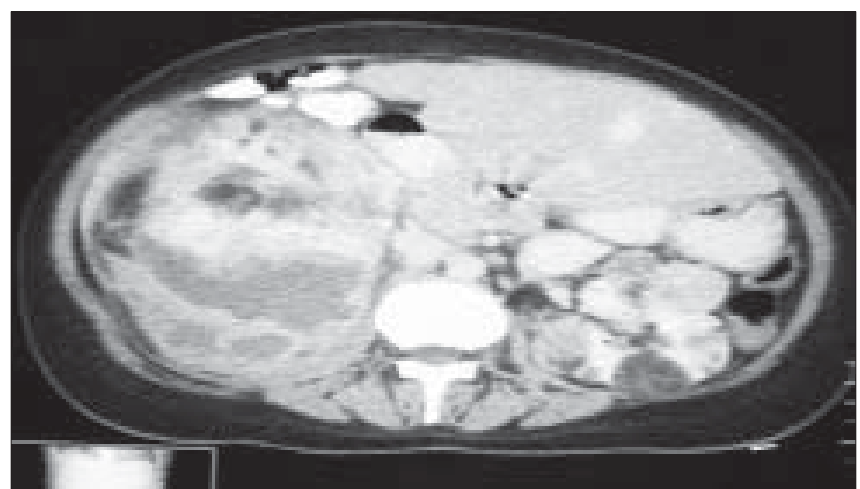

Figure 1: Bilateral renal angiomyolipoma with right intra-renal hemorrhage

seen to be arising from the left lobe of liver with presence of multiple fat density areas suggestive of hepatic angiomyolipoma [Figure 2]. A diagnosis of Tuberous Sclerosis with bilateral renal angiomyolipomas with $\mathrm{H}$ epatic Angiomyolipoma with spontaneous rupture of right renal AM L [Wunderlich's Syndrome] was made. As the patient had bilateral renal disease, DMSA scan was done to identify any functional cortical tissue on the right side. It revealed some viable cortical tissue in the upper third of the right kidney in association with multiple photopenic areas in the left kidney. Right renal angiogram was done which showed increased vascularity and multiple aneurysmal dilations, characteristics of angiomyolipoma [Figure 3]. H owever no definite feeding vessel could be identified and salvage of right upper pole of kidney was not possible. Right $\mathrm{N}$ ephrectomy was done. Biopsy was taken from Liver $S O L$ as the patient did not consent to surgery for asymptomatic hepatic angiomyolipoma. Postoperative period was uneventful. Biopsy from kidney as well as $\mathrm{H}$ epatic lesion revealed Angiomyolipoma.

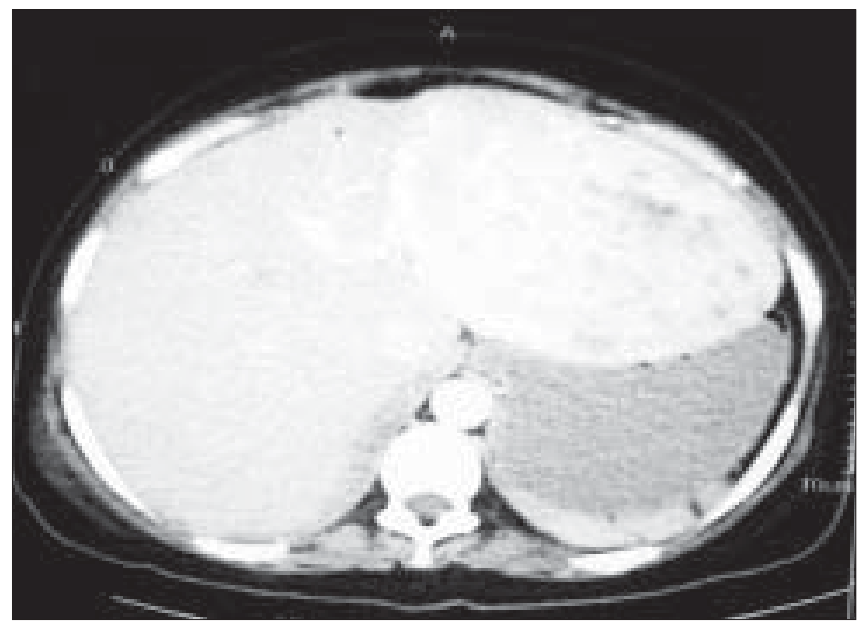

Figure 2: CT-scan showing multiple fat density areas suggestive of hepatic angiomyolipoma

\section{Discussion}

Wunderlich's syndrome refers to spontaneous nontraumatic renal bleeding into the subcapsular and/or perirenal space. Radiology plays an important role in the evaluation of patients with this clinical problem. Patients may present with the classic triad of symptoms-acute abdominal pain, a palpable mass and hypovolemic shock. Common causes of Wunderlich's syndrome include benign and malignant renal tumors, vascular lesions like polyarteritis nodosa, renal infections, nephritis, previously undiagnosed hematological conditions and anatomical lesions like cysts and hydronephrosis. ${ }^{[2]}$ The commonest cause of spontaneous renal hemorrhage in most series is an angiomyolipoma. ${ }^{[3]}$ It has an incidence of about $0.3-3 \%$ and 2 types are described: isolated angiomyolipoma and angiomyolipoma that is associated with tuberous sclerosis. ${ }^{[4]}$ Approximately $20 \%$ to $30 \%$ of AMLS are found in patients with tuberous sclerosis syndrome (TS), an autosomal dominant disorder characterized by mental retardation, epilepsy and adenoma sebaceum, a distinctive skin lesion. In contrast, of the $70 \%$ to $80 \%$ of patients with AML who do not have TS, a more pronounced female predominance is found and most patients present later in life, during the fifth or sixth decade.

$\mathrm{H}$ epatic angiomyolipoma is very rare. $\mathrm{HAML}$ is a benign lesion and often grows slowly without any clinical symptoms. Spontaneous rupture, later recurrence and vascular invasion of HAML have been reported. ${ }^{[5]}$ The normal appearance of the liver on unenhanced $C T$ scans is homogeneous, with attenuation values of 40 $70 \mathrm{HU}$. For the most part, hepatic malignancies have somewhat lower attenuation values on unenhanced scans (35-50 HU). Masses with densities of 20-30

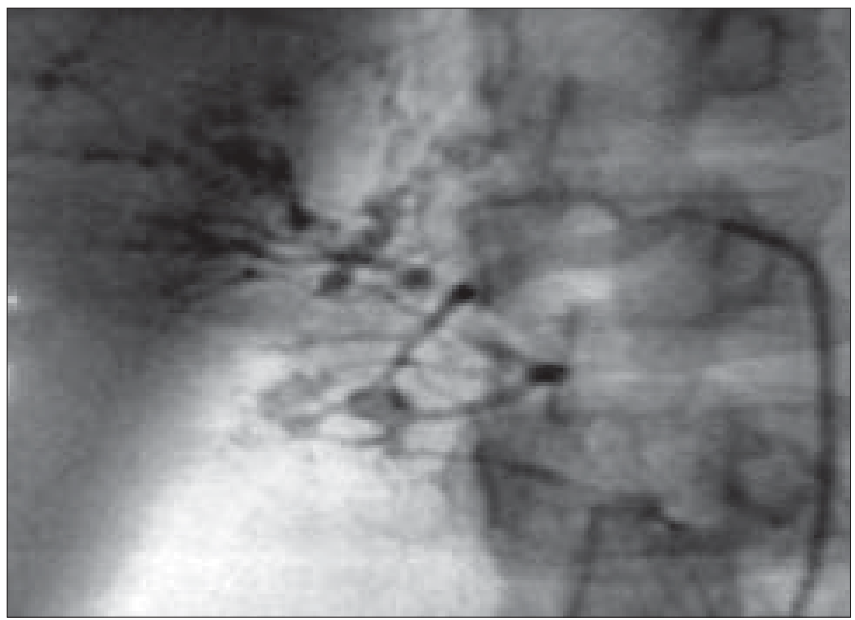

Figure 3: Right renal angiogram showing increased vascularity and multiple aneurysmal dilations 
H U suggest tumor degeneration or necrosis. $\mathrm{H}$ epatic cysts will normally have an attenuation of -5 to +10 $\mathrm{HU}$. Focal masses with attenuation values of less than $-20 \mathrm{HU}$ indicate definite fatty tissue as was in our case. ${ }^{[6]}$ Although diagnosis may be suggested by imaging methods, histological confirmation is mandatory. The true incidence of angiomyolipomas or lipomatous tumors in the liver is not known because of the difficulty in detection. The detectability of these lesions is limited by the following facts: 1) fatty tumors are rare, 2) fat is difficult to detect in lesions with a low fat content, 3) the lesions are asymptomatic and hence are detected only as incidental findings, 4) small lesions can be confused for a simple cyst due to partial volume averaging and 5) a peripheral mass or one adjacent to the fat-containing falciform ligament is difficult to appreciate. In fact, the cases of tuberous sclerosis associated with hepatic multiple lipomatous tumors are rare although, nearly half of all cases of angiomyolipoma in the kidney are reported as an occasional association with tuberous sclerosis complex. H owever, since several cases of tuberous sclerosis associated with hepatic lipoma or angiomyolipoma have been reported, hepatic angiomyolipoma is classified as minor criteria of tuberous sclerosis complex. ${ }^{[7]}$

Conservative management with close follow-up can be offered to a well informed patient especially if the patient is asymptomatic and size is smaller than $5 \mathrm{~cm}$. Surgery is recommended for patients with symptoms, for patients in whom diagnostic imaging cannot exclude malignancy and for patients in whom the tumor enlarges obviously in short time or shows extra hepatic growth and has a risk of spontaneous rupture. ${ }^{[2]} \mathrm{H}$ epatic angiomyolipomas though rare, may be found in patients with tuberous sclerosis and particularly in patients with bilateral diffuse renal angiomyolipomas. The finding of multiplehepatic angiomyolipomas in a patient not diagnosed with tuberous sclerosis is reason to evaluate for further evidence of tuberous sclerosis.

Wunderlich's syndrome is one of the most feared complications of renal angiomyolipoma and should be managed aggressively. $\mathrm{N}$ ephron sparing approach such as angio-embolisation and partial nephrectomy is preferable, especially in TS with bilateral and multicentric angiomyolipomas. Most patients with acute life-threatening hemorrhage or non salvageable renal unit require total nephrectomy. The finding of multiple hepatic angiomyolipomas in a patient with tuberous sclerosis should not be surprising or provoke unnecessary treatment in asymptomatic cases. These patients need strict follow-up for the rate of increase of both renal as well as hepatic lesion.

\section{References}

1. Albi G, del Campo L, Taggaro D. Wünderlich's syndrome: Causes, diagnosis and radiological management. Clin Radiol 2002;57:840-5

2. Ren N, Qin LX, Tang ZY, Wu ZQ, Fan J. Diagnosis and treatment of hepatic angiomyolipoma in 26 cases. World J Gastroenterol 2003;9:1856-8.

3. Zhang JQ, Feilding JR, Zou KH. Etiology of spontaneous perirenal hemorrhage: A meta-analysis. J Urol 2002;167:1593-6.

4. Rakowski SK, Winterkorn EB, Paul E, Steele DJ, Halpern EF, Thiele EA. Renal manifestations of tuberous sclerosis complex: Incidence, prognosis and predictive factors. Kidney Int 2006;70:1777-82.

5. Guidi G, Catalano O, Rotondo A. Spontaneous rupture of a hepatic angiomyolipoma: CT findings and literature review. Eur Radiol 1997;7:335-7.

6. Roberts JL, Fishman EK, Hartman DS, Sanders R, Goodman Z, Siegelman SS. Lipomatous tumors of the liver: Evaluation with CT and US. Radiology 1986;158:613-7.

7. Hirasaki S, Koide N, Ogawa H, Ujike K, Shinji T, Tsuji T. Tuberous sclerosis associated with multiple hepatic lipomatous tumors and hemorrhagic renal angiomyolipoma. Int Med 1999;38:345-8.

\section{Author Help: Reference checking facility}

The manuscript system (www.journalonw eb.com) allows the authors to check and verify the accuracy and style of references. The tool checks the references with PubM ed as per a predefined style. Authors are encouraged to use this facility before submitting articles to the journal.

- The style as well as bibliographic elements should be $100 \%$ accurate to get the references verified from the system. A single spelling error or addition of issue number / month of publication will lead to error to verifying the reference.

- Example of a correct style

Sheahan P, O'leary G, Lee G, Fitzgibbon J. Cystic cervical metastases: Incidence and diagnosis using fine needle aspiration biopsy. Otolaryngol Head Neck Surg 2002;127:294-8.

- Only the references from journals indexed in PubM ed would be checked.

- Enter each reference in new line, without a serial number.

- Add up to a maximum 15 reference at time.

- If the reference is correct for its bibliographic elements and punctuations, it will be shown as CORRECT and a link to the correct article in PubM ed will be given.

- If any of the bibliographic elements are missing, incorrect or extra (such as issue number), it will be show $n$ as INCORRECT and link to possible articles in PubM ed will be given. 